Received: 11 March 2019, Revised: 19 March 2019

Accepted: 11 April 2019, Published: 28 April 2019

Available online at: http://e-journal.unair.ac.id/index.php/IMHSJ

\title{
PENGARUH AKTIVITAS FISIK DAN USIA MENARCHE DENGAN KEJADIAN PREMENSTRUAL SYNDROME PADA REMAJA PUTRI
}

\section{THE EFFECT OF PHYSICAL ACTIVITY AND AGE OF MENARCHE WITH PREMENSTRUAL SYNDROME TO FEMALE ADOLESCENTS}

\author{
Ziah Datul Kamilah', Budi Utomo², Baksono Winardi ${ }^{2}$
}

\author{
1. Program Studi Pendidikan Bidan, Fakultas Kedokteran, Universitas \\ Airlangga Surabaya \\ 2. Fakultas Kedokteran, Universitas Airlangga \\ Alamat korespondensi: \\ J1. Martapura Lama, Banjarmasin, 70238 Indonesia \\ Email: ziahdatulk@gmail.com
}

\begin{abstract}
Abstrak
Latar Belakang: Premenstrual syndrome merupakan munculnya gejala yang dirasakan baik fisik, emosi maupun perilaku sehingga berakibat adanya stres yang dapat berulang setiap adanya fase sebelum menstruasi. Efek dari PMS tersebut dapat sampai mengganggu aktivitas dan konsentrasi belajar terutama pada siswi yang masih sekolah. Studi pendahuluan yang sudah dilakukan di SMP Negeri 29 Surabaya diketahui data dari catatan perbulan UKS bahwa terdapat siswi yang masuk UKS dikarenakan mengeluh sakit perut, pusing dan mual sebelum menstruasi, setelah dilakukan wawancara sebanyak 15 siswi terdapat 15 yang mengalami gejala premenstrual syndrome dengan tingkatan yang berbeda-beda. Penelitian ini bertujuan untuk mempelajari hubungan antara aktivitas fisik dan usia menarche dengan kejadian premenstrual syndrome. Metode: Penelitian ini adalah penelitian analitik observasional dengan pendekatan cross sectional. Jumlah sampel sebanyak 206 siswi sesuai dengan kriteria inklusi. Sampling dilakukan dengan simple random sampling. Variabel independen dalam penelitian ini adalah aktivitas fisik dan usia menarche, sedangkan variabel dependennya adalah kejadian premenstrual syndrome. Cara mengetahui tingkat signifikan, data yang sudah terkumpul diuji dengan uji statistik Chi-square pada tingkat kemaknaan $\alpha=0,05$. Hasil penelitian yang didapatkan bahwa sebesar 57,6\% remaja putri melakukan aktivitas fisik dengan kategori rendah, 29,8\% remaja putri mengalami menarche dini, dan sebesar $71,2 \%$ remaja putri mengalami premenstrual syndrome ringan. Hasil: Hasil penelitian setelah dilakukan uji Chi-square diperoleh untuk aktivitas fisik nilai $\mathrm{p}=0,030(\mathrm{p} \leq 0,05)$ yang berarti ada hubungan antara aktivitas fisik dengan kejadian premenstrual syndrome, dan untuk usia menarche nilai $\mathrm{p}=0,073(\mathrm{p} \geq 0,05)$ yang berarti tidak ada hubungan antara usia menarche dengan kejadian premenstrual syndrome. Kesimpulan: Kebiasaan untuk beraktivitas fisik yang tepat dan rutin serta mengurangi stres dapat mengatasi dan mengurangi keluhan premenstrual syndrome yang dialami.
\end{abstract}

Kata kunci: Aktivitas Fisik, Usia menarche, Premenstrual syndrome

\section{Abstract}

Background: Premenstrual syndrome (PMS) is the symptoms that are felt both physically and emotionally as well as behaviorally, resulting in stress that can recur at every phase before menstruation. The effects of PMS can interfere in learning activity and concentration of female students who are still at school. Preliminary studies conducted at SMP Negeri 29 Surabaya and monthly data records from its UKS revealed that there were students who entered UKS because they experienced abdominal pain, dizziness and nausea before menstruation. After conducting an interview to 15 female students, there were 15 students who experienced symptoms of premenstrual e-ISSN 2656-7806 C 2019 
syndrome at different levels. This research aims to study the relationship between physical activity and age of menarche with premenstrual syndrome. Method: This study was an observational analytic study with a cross sectional approach. The total sample was 206 students according to the inclusion criteria. Sampling is done by using simple random sampling. The independent variable in this research is physical activity and age of menarche, while the dependent variable is the phenomena of premenstrual syndrome. The significant level can be found out by testing the collected data using Chi-square statistical test with the significant level $\alpha=0.05$. The results showed that $57.6 \%$ of female adolescents did physical activity in a low category, $29.8 \%$ of female adolescents had early menarche, and $71.2 \%$ of female adolescents had mild premenstrual syndrome. Results: The results of the Chi-square test showed that physical activity's value $p=0.030(p \leq 0.05)$ means that there is a relationship between physical activity and the phenomena of premenstrual syndrome, and age of menarche's value $p=0.073(p \geq 0,05)$ means that there is no relationship between age of menarche and the phenomena of premenstrual syndrome. Conclusion: Habits for proper and routine physical activity and reducing stress can overcome and reduce the symptoms of premenstrual syndrome.

Keywords: Physical Activity, Age of menarche, Premenstrual syndrome

\section{PENDAHULUAN}

Premenstrual syndrome atau sering disebut dengan PMS adalah ketidaknyamanan yang dirasakan oleh perempuan yang sudah mengalami menstruasi atau sudah memasuki usia reproduktif, ketidaknyamanan tersebut dapat dirasakan secara fisik dan emosi pada 7 sampai 14 hari sebelum datangnya menstruasi (Rahayu, 2017). PMS merupakan hal yang berbeda dengan dismenore, PMS melibatkan beberapa gejala baik itu fisik maupun emosional dan dapat muncul sekitar 2 minggu sebelum datangnya haid serta dapat menghilang saat haid atau tetap berlanjut hingga haid selesai sedangkan dismenore merupakan nyeri haid yang muncul bersamaan saat datangnya haid (Sibagariang, 2016).

Faktor risiko dari munculnya premenstrual syndrome adalah terdiri dari berbagai sisi yaitu dapat dari faktor eksternal yang terdiri lingkungan, stresor, status perkawinan, nutrisi dan aktivitas fisik. Aktivitas fisik menjadi salah satu faktor dalam merangsang otak untuk memproduksi serotonin dimana fungsi serotonin dapat mengurasi stres sehingga jika kurang beraktivitas fisik tentu produksi serotonin pun akan ikut menurun sehingga dapat meningkatkan timbulnya stres dan berlanjut akan munculnya beberapa gejala PMS baik fisik maupun emosional sehingga remaja akan mengalami premenstrual syndrome, pada faktor internal dapat dikarenakan genetik, gangguan perasaan, kejiwaan, hormonal dan usia menarche. Usia menarche dapat memengaruhi munculnya gejala PMS karena menarche dini dapat membuat remaja putri memiliki pengetahuan yang kurang karena menstruasi datang lebih dini sehingga berpeluang untuk belum siapnya 
dalam menghadapi perubahan diri yang dialami remaja putri serta disisi lain menarche dini dapat membuat remaja lebih banyak terpapar akan ketidakseimbangan hormon karena produksi hormon reproduksi lebih dini aktif (Sibagariang, 2016).

Gejala PMS merupakan gabungan dari beberapa gejala fisik dan emosional yang kemudian dapat dirasakan secara ringan, sedang maupun berat oleh remaja putri sehingga dapat disebut PMS atau premenstrual syndrome (Sibagariang, 2016). Penelitian ini bertujuan untuk menganalisis pengaruh aktivitas fisik dan usia menarche terhadap PMS, penyebab yang dapat memicu maupun yang memperberat PMS sehingga dapat dilakukan pencegahan dan untuk mengurangi kejadian PMS pada remaja putri. Hal tersebut tentu sangat berguna terutama bagi remaja putri yang mengalami sindrom pramenstruasi maupun bagi remaja yang tidak mengalami gejala PMS untuk melakukan pencegahan.

\section{METODE}

Tempat penelitian ini dilakukan di SMP N 29 Surabaya.

Desain penelitian menggunakan cross sectional. Populasinya adalah siswi kelas VII dan VIII berjumlah 382 siswi.

Teknik sampling yang digunakan adalah probability sampling berdasarkan kriteria inklusi hingga didapatkan jumlah 206 responden sesuai dengan rumus yang ditentukan.

Pengumpulan data dengan cara siswi mengisi kuesioner tingkat aktivitas fisik remaja yang diadaptasi dari WHO yaitu GPAQ (Global Physical Activity Questionnaire) dan kuesioner tingkat premenstrual syndrome diadaptasi dari jurnal penelitian Padmavathi et al, (2014) yaitu Premenstrual Syndrome Scale (PMSS) untuk mendapatkan data primer.

Analisis data pada penelitian ini menggunakan uji Chi-square dengan tingkat kemaknaan 0,05 untuk mengetahui hubungan antara aktivitas fisik dan usia menarche dengan kejadian premenstrual syndrome.

\section{HASIL DAN PEMBAHASAN}


Tabel 1. Data Hubungan Aktivitas Fisik Dengan Kejadian Premenstrual Syndrome Pada Remaja Putri.

\begin{tabular}{|c|c|c|c|c|c|c|c|c|c|c|}
\hline & \multicolumn{9}{|c|}{ PMS } & \multirow{3}{*}{$\begin{array}{c}\text { Nilai } \\
\mathbf{p} \\
0,030\end{array}$} \\
\hline & & \multicolumn{2}{|c|}{ Ringan } & \multicolumn{2}{|c|}{ Sedang } & \multicolumn{2}{|c|}{ Berat } & \multicolumn{2}{|c|}{ Total } & \\
\hline & & $\mathrm{N}$ & $\%$ & $\mathrm{~N}$ & $\%$ & $\mathrm{~N}$ & $\%$ & $\mathrm{~N}$ & $\%$ & \\
\hline \multirow{3}{*}{$\begin{array}{c}\text { Aktivitas } \\
\text { Fisik }\end{array}$} & Rendah & 91 & 76,5 & 28 & 23,5 & 0 & 0 & 119 & 100 & \\
\hline & Seda & 41 & 68,3 & 19 & 31,7 & 0 & 0 & 60 & 100 & \\
\hline & Tinggi & 15 & 55,6 & 11 & 40,7 & 1 & 3,7 & 27 & 100 & \\
\hline
\end{tabular}

Hasil uji statistik didapatkan bahwa ada hubungan aktivitas fisik dengan kejadian premenstrual syndrome pada remaja putri kelas VII dan VIII SMP Negeri 29 Surabaya. Data yang dapat dilihat pada tabel 1 menunjukkan bahwa semakin tinggi responden melakukan aktivitas fisik semakin berat premenstrual syndrome yang dialami. Aktivitas fisik dengan intensitas tinggi hingga sangat tinggi dengan waktu yang lama dapat mengakibatkan stres dikarenakan tingkat kelelahan yang juga tinggi sehingga hal tersebut juga memengaruhi munculnya gejala premenstrual syndrome (Quindry J.,et al,2015). Aktivitas fisik yang rutin dengan olahraga yang tepat dapat mengurangi keluhan premenstrual syndrome yang dialami dikarenakan olahraga dapat meningkatkan kadar endorphin, sehingga menurunkan kadar hormon kortisol dan dapat mengurangi stres, serta melancarkan pengangkutan oksigen dalam tubuh (Desrosiers et al., 2017). Beraktivitas fisik dan olahraga yang tepat dan teratur dapat mengurangi gejala sindrom prahaid yang dialami (Mohebbi Dehnavi, Jafarnejad dan Sadeghi Goghary, 2018).

Faktor risiko terjadinya premenstrual syndrome adalah zat-zat gizi yang rendah dalam tubuh seperti kekurangan vitamin B6, C, E, magnesium, Fe, kebiasaan dalam makan seperti mengonsumsi makanan dengan tinggi gula dan garam serta kebiasaan minum kopi dan soda, serta stres sehingga perlu diperhatikan adanya faktor lain yang memicu dan memperberat gejala premenstrual syndrome yang dialami (Sibagariang, 2016). Data yang didapat dari penelitian ini diketahui bahwa semakin berat aktivitas fisik yang dilakukan semakin berat sindrom pramenstruasi yang dialami, jadi dapat diketahui bahwa premenstrual syndrome memiliki banyak faktor pemicu, seperti stres yang dapat dipicu oleh banyak penyebab contohnya keadaan yang sering terjadi disekolah yaitu siswi yang akan menghadapi perlombaan baik dalam dibidang akademik dan non akademik yang sering diikuti oleh siswa dan siswi SMP N 29 Surabaya maupun dalam proses 
belajar, penerapan fullday school juga dapat menjadi salahsatu pemicu stres pada siswi SMP N 29 Surabaya dikarenakan proses belajar yang lebih panjang, sosial dan tingkat ekonomi, permasalahan dilingkungan keluarga, sekolah maupun pertemanan yang dapat memperparah stres sehingga pencetus premenstrual syndrome ini tidak dapat hanya dilihat 1 atau 2 faktor saja namun perlu dilihat lebih dalam lagi karena pemicu stres setiap individu berbeda-beda.

Tabel 2. Data Hubungan Usia Menarche Dengan Kejadian Premenstrual Syndrome Pada Remaja Putri.

\begin{tabular}{|c|c|c|c|c|c|c|c|c|c|c|}
\hline & \multicolumn{9}{|c|}{ PMS } & \multirow{5}{*}{$\begin{array}{c}\text { Nilai } \\
\mathbf{p} \\
0,073\end{array}$} \\
\hline & & \multicolumn{2}{|c|}{ Ringan } & \multicolumn{2}{|c|}{ Sedang } & \multicolumn{2}{|c|}{ Berat } & \multicolumn{2}{|c|}{ Total } & \\
\hline & & $\mathrm{N}$ & $\%$ & $\mathrm{~N}$ & $\%$ & $\mathrm{~N}$ & $\%$ & $\mathrm{~N}$ & $\%$ & \\
\hline \multirow[t]{2}{*}{$\begin{array}{c}\text { Usia } \\
\text { Menarche }\end{array}$} & $\begin{array}{l}<12 \text { tahun atau } \\
\text { menarche dini }\end{array}$ & 38 & 62,3 & 23 & 37,7 & 0 & 0 & 61 & 100 & \\
\hline & $\begin{array}{l}>12 \text { tahun atau } \\
\text { tidak menarche } \\
\text { dini }\end{array}$ & 109 & 75,2 & 35 & 24,1 & 1 & 0,7 & 145 & 100 & \\
\hline
\end{tabular}

Berdasarkan tabel 2 Menunjukkan bahwa responden dengan tidak menarche dini mengalami premenstrual syndrome ringan sebanyak 109 responden atau 75,2\%. Hasil uji statistik menggunakan chi-square didapatkan bahwa tidak ada hubungan antara usia menarche dengan kejadian premenstrual syndrome pada remaja putri kelas VII dan VIII SMP Negeri 29 Surabaya. Hasil penelitian responden dengan menarche dini mengalami premenstrual syndrome dengan tingkat ringan sebanyak $62,3 \%$ dan tingkat sedang sebanyak $37,7 \%$ serta responden yang tidak mengalami menarche dini yang mengalami premenstrual syndrome ringan sebanyak $75,2 \%$ dan tingkat sedang sebanyak 24,1\%. Dilihat dari data distribusi frekuensi ada kecenderungan bahwa remaja putri yang mengalami menarche dini mengalami premenstrual syndrome lebih berat daripada remaja putri dengan tidak menarche dini yaitu dilihat dari persentase remaja putri mengalami premenstrual syndrome tingkat sedang lebih besar pada remaja putri dengan menarche dini.

Penelitian Ratikasari (2015) menyimpulkan bahwa tidak ada hubungan antara usia menarche dengan kejadian sindrom prahaid atau premenstrual syndrome, namun dilihat dari distribusi frekuensinya, remaja dengan menarche dini lebih banyak mengalami sindrom prahaid dengan tingkatan sedang hingga berat daripada remaja dengan tidak menarche dini. Menarche dini dapat memperbesar peluang untuk mengalami sindrom prahaid dapat dikarenakan usia remaja yang masih muda namun sudah mengalami menstruasi sehingga lebih dini dan sering 
mengalami ketidakseimbangan hormon reproduksi karena salah satu penyebab terjadinya sindrom pramenstruasi adalah adanya ketidakseimbangan hormon estrogen dan progesteron. Usia yang masih muda juga dapat berkaitan dengan kurang matangnya pengendalian emosi sehingga remaja putri yang mengalami menarche dini dapat kurang mengontrol emosi dan dapat terjadi ketegangan emosi sehingga berakibat meningkatkan tingkat stres sehingga dapat mengalami sindrom prahaid (Devi, 2013). Usia menarche perempuan di Indonesia cenderung semakin dini setiap tahunnya yaitu dilihat dari tahun 1970 sampai 2010 usia menarche mengalami percepatan usia 8,9 hari pertahunnya, hal tersebut dapat dikarenakan perkembangan ekonomi dan sosial di Indonesia (Wahab et al, 2018). Usia menarche yang semakin muda menjadi semakin kurang stabil dalam emosi dan kurang persiapan dalam hal menghadapi menstruasi bagi remaja putri, serta adanya perasaan terbebani yaitu merasa masih sangat muda namun sudah mengalami menstruasi.

\section{SIMPULAN DAN SARAN}

Ada hubungan antara aktivitas fisik dengan kejadian premenstrual syndrome pada remaja putri kelas VII dan VIII SMP N 29 Surabaya. Tidak ada hubungan antara usia menarche dengan kejadian kejadian premenstrual syndrome pada remaja putri kelas VII dan VIII SMP N 29 Surabaya. Masyarakat, remaja putri dan orangtua dapat lebih meningkatkan perhatian dan pengetahuan tentang faktorfaktor yang dapat memperparah dan meringankan kejadian premenstrual syndrome yang dialami sehingga gejala saat masa pramenstruasi tidak mengganggu aktivitas seperti mengatasi pemicu stres baik dilingkungan keluarga atau rumah maupun lingkungan sekolah yang memengaruhi tingkat keparahan sindrom pramenstruasi. Penelitian selanjutnya dapat menambahkan faktor atau variabel lain terutama tentang tingkat stres, sosial, ekonomi dan menambah jumlah sampel diberbagai jenjang pendidikan dan kelas agar memperkaya hasil penelitian. 


\section{DAFTAR PUSTAKA}

Kroll-Desrosiers, A. R. et al. (2017) 'Recreational Physical Activity and Premenstrual Syndrome in Young Adult Women: A Cross-Sectional Study', PLOS ONE, 12(1), p. e0169728. Available at: https://doi.org/10.1371/journal.pone.0169728.

Mohebbi Dehnavi, Z., Jafarnejad, F. dan Sadeghi Goghary, S. (2018) "The effect of 8weeks aerobic exercise on severity of physical symptoms of premenstrual syndrome: A clinical trial study," BMC Women's Health, 18(1), hal. 1-7. doi: 10.1186/s12905-018-0565-5.

Devi, M. (2013)'Gizi saat sindrom menstruasi'. Jakarta: BIP Kelompok Gramedia, hal.3-7.

Quindry J, Dumke C, Slivka D, Ruby B. (2015) 'Impact of extreme exercise at high altitude on oxidative stres in humans', J Physiol, vol. 594, no.18

Rahayu, A. (2017) 'Kesehatan reproduksi remaja dan lansia'.Surabaya: Airlangga University Press, hal. 31-35.

Ratikasari, I. (2015) 'Faktor-faktor yang berhubungan dengan kejadian sindrom pramenstruasi (PMS) pada siswi SMA 112 jakarta tahun 2015'. Skripsi. Universitas Islam Negeri Syarif Hidayatullah Jakarta.

Sibagariang, E. (2016). 'Kesehatan reproduksi wanita'. Jakarta: Trans Info Media, hal. 88-93.

Wahab, A., Wilopo, S., Hakimi, M. and Ismail, D. (2020) Declining age at menarche in Indonesia: a systematic review and meta-analysis. International Journal of Adolescent Medicine and Health, Vol. 32 (Issue 6), pp. 20180021. https://doi.org/10.1515/ijamh-2018-0021 